\title{
Building and using Economic Models: a Case Study Analysis of the IS-LL Model
}

Citation for published version (APA):

Dohmen, T. J. (2002). Building and using Economic Models: a Case Study Analysis of the IS-LL Model. Journal of Economic Methodology, 9(2), 191-212. https://doi.org/10.1080/13901780210137100

Document status and date:

Published: 01/01/2002

DOI:

10.1080/13901780210137100

Document Version:

Publisher's PDF, also known as Version of record

\section{Please check the document version of this publication:}

- A submitted manuscript is the version of the article upon submission and before peer-review. There can be important differences between the submitted version and the official published version of record.

People interested in the research are advised to contact the author for the final version of the publication, or visit the DOI to the publisher's website.

- The final author version and the galley proof are versions of the publication after peer review.

- The final published version features the final layout of the paper including the volume, issue and page numbers.

Link to publication

\footnotetext{
General rights rights.

- You may freely distribute the URL identifying the publication in the public portal. please follow below link for the End User Agreement:

www.umlib.nl/taverne-license

Take down policy

If you believe that this document breaches copyright please contact us at:

repository@maastrichtuniversity.nl

providing details and we will investigate your claim.
}

Copyright and moral rights for the publications made accessible in the public portal are retained by the authors and/or other copyright owners and it is a condition of accessing publications that users recognise and abide by the legal requirements associated with these

- Users may download and print one copy of any publication from the public portal for the purpose of private study or research.

- You may not further distribute the material or use it for any profit-making activity or commercial gain

If the publication is distributed under the terms of Article $25 \mathrm{fa}$ of the Dutch Copyright Act, indicated by the "Taverne" license above, 


\title{
Building and using economic models: a case study analysis of the IS-LL model
}

\author{
Thomas J. Dohmen
}

\begin{abstract}
This paper critically assesses several model accounts written in the 1990s by epistemologists and philosophers of science by relating them to a specific but crucial example of model building, namely Hicks's (1937) construction of the first version of the IS-LM model, and examining in how far these accounts apply to this case. Thereby the paper contributes to answering why and how economists build models. The view crystallizes that economists build models not only to facilitate the conceptual exploration of theory, but also to inform our understanding of the world. Elements of model building, such as analogies, metaphors, stories, theoretical notions, empirical findings and mathematizations, but also the mode of representation shape the model and largely determine how much can be learned about theory and the real world by using the model as a tool.
\end{abstract}

Keywords: economic methodology, modeling, IS-LL model, philosophy of economic models.

\section{INTRODUCTION}

The language of models has permeated the recent social science literature. Scientific articles in economic journals without reference to a model or usage of the term 'model' are rare nowadays. Not least the important role that models have come to play in scientific discourse has motivated philosophers of science and practicing economists to propose answers to questions like why do economists build models, how do they go about constructing models, how do models function, and how do we learn from them.

This paper is intended as one step towards achieving the ultimate goal of providing answers to these questions. Conscious of the vast variety in the way economists build and use models, I consider a specific but crucial example of model building, the construction of the first version of the IS-LM model, and use it as a litmus test to throw light on issues raised in model accounts of the modern methodological literature written by Boumans (1999), Gordon (1991), Hausman (1992), Hughes (1997), Klamer and Leonard (1994), Morgan and Morrison (1999), Morgan (1999a, 1999b) and Psillos (1995) which are all concerned with models of (economic) theorists rather than with econometric models and empirical work. By critically assessing which 
elements of these accounts fit to Hicks's model, I seek to contribute to an explanation why and how economists build models.

Hicks (1937) constructed the IS-LL model in a paper he presented at the Econometric Society meetings at Oxford in 1936 in a symposium on Keynes's General Theory. The status of what is now known as the IS-LM model as one of the most influential macroeconomic models is evident considering the large number of extensions and modifications that were made to incorporate a host of phenomena and theoretical ideas, including, for example, the $q$-theory of investment, portfolio and wealth effects, menu costs, adaptive and rational expectations, flows of funds, the government budget constraint, a distinction between inside and outside money, a foreign sector, increasing returns to scale, etc.

Obviously the IS-LM apparatus appeared helpful to many economists. But in what sense is the model useful? What makes a successful model and how is it built? Such questions will guide the search for explanations in the following paragraphs. But before proceeding to the core of the analysis in Sections 4-6, a distinction between the term 'model' and 'theory' is made (Section 2) as it is a prerequisite for the argument and the communication of it, and crucial issues raised in model accounts of the modern methodological literature are reviewed (Section 3). Finally, Section 7 concludes the paper.

\section{THEORIES AND MODELS}

'Theory' and 'model' are frequently used as interchangeable terms in scientific economic discourse. However, a clear distinction between the terms 'model' and 'theory' is not only generally useful, but it is indispensable for the issues addressed in this paper. I therefore offer, without claim to originality, a definition of these terms. ${ }^{1}$

I suggest to think of economic 'theories' as organized bodies of ideas about the truth and functioning of the economy, or as Axel Leijonhufvud proposes, 'as sets of beliefs about the economy and how it functions (Leijonhufvud 1997: 193). Such a system of beliefs is (built on) a body of assertions or principles that can sometimes be tested empirically. Beliefs and consequently theories might either be derived from the study of 'empirical facts' or 'laws' relating to it, or be the result of speculative imagination, which, regardless of their origin, give rise to the formulation of hypotheses. In developing a theory one proceeds from axioms as well as from hypotheses that are verifiable. The rejection of a hypothesis as valid might give rise to the formulation of new hypotheses. Theories, as organized bodies of hypotheses, help to abstract fundamental aspects of a complex 'real world', facilitate systematic reasoning and foster the formulation of new hypotheses. 'The theory level is the economist's working habitat, where the economist's thinking is done [ . . ]' (Leijonhufvud 1997: 195).

Models represent a theory in an idealized world and are less complex. In 
other words, models are simplified, partial statements of theories. Models serve the purpose of demonstrating (part of) a theory and are in this sense a vehicle of communication for a theory. Models do not make assertions, but rest on assumptions. Since models are only constructs consisting of assumptions, they cannot be tested. The assumptions of a model might be appropriate or not, but that can at best give rise to the conclusion that a model is 'correct' or 'incorrect', but not - as holds true for a theory - that it is 'true' or 'false'. Another facet highlighting that models are representations of theories and which might contribute to a conceptual distinction between theories and models is addressed by Leijonhufvud: 'Since models are simplified, partial statements of theories, several models may belong to the same theory, designed to elucidate different aspects of it. More interestingly - and confusingly - the same model may sometimes be derived from more than one theory (Leijonhufvud 1997: 194).

Different modes of representation may emphasize distinct theoretical aspects. What is more, alternative representations might have varying success in helping us to discover novel relations, thereby enlarging our theoretical knowledge and our understanding of the real world. A kaleidoscopic variety of economic models exists within the class of theoretical models - some being principally deductive, others mainly metaphoric, again others are primarily of a narrative type. This variety has given rise to several model accounts, some of which are called on below and which will further illuminate what models are, why economists build them and how they facilitate theorizing and advance our understanding of the world.

\section{MODEL ACCOUNTS IN THE MODERN METHODOLOGICAL LITERATURE}

Several model accounts written in the 1990s deal with the question of why scientists in general or economists in particular build models. These accounts generally agree that scientists build models to learn from them. Yet, they disagree on what the relation between theory, a model and the 'real world' is, what scientists learn about, how and why models can serve as a learning device, and how scientists learn from models.

Scott Gordon argues that 'the purpose of any model is to serve as a tool or instrument of scientific investigation' (Gordon 1991: 108). He is vague on what we learn about, but he stresses that models make complex real-world matters or processes comprehensible. Simplification is key for him: 'The whole point in building an analytical model is to construct a representation that is simpler that the real thing' (Gordon 1991: 109).

Koopmans (1957) had already articulated the view that economists build models to convey a complicated reality in a simpler way. Following Robbins (1984), Koopmans stresses in his account that propositions of economic theory are deductions from a series of postulates. ${ }^{2}$ Implications for the real 
world follow from assumptions by deductive reasoning. Evidence and observation influence assumptions via induction. Starting from a simple idealized theory, theory should be developed in an ordered sequence with increasing realism that allows tracing implications to the postulates on which they rest. This is contrary to Friedman's (1953) position who suppresses the question about the realism of assumptions arguing that the validity of any set of postulates only depends on the predictive power of the theory.

Hausman (1992) proposes that economists build models to explore their theories. 'Such model-building [...] does not presuppose that one believes that the particular model is of any use in understanding the world' (Hausman 1992: 26). As long as a model only serves to explore and develop new theoretical concepts, the question about the realism of assumptions can be rejected: "Unrealistic" model-making is an unavoidable occupation of theoretically inclined economists' (Hausman 1992: 27). This does, however, not necessarily support Friedman's (1953) view. On the contrary, Hausman warns that 'models have little value (apart from their mathematical interest) unless they can be applied - unless they enable us to make true or reliable assertions about the world' (Hausman 1992: 27). ${ }^{4}$

Morrison and Morgan (1999) do not agree with Hausman's perception that a lot of modeling is aimed at understanding theory and not so much to model the real world. Instead they argue that models function "to help us to learn not only about theories but also about the world' (Morrison and Morgan 1999: 10). Morgan (1999b) focuses on the relation of models to the world, claiming that models help to explain and understand the world by telling stories about the world we live in. Morrison and Morgan (1999) emphasize the role of models as instruments and argue that models mediate between theory and the real world. ${ }^{5}$ The mediating power stems from a relation to theory and to the world mixed with partial independence from both. The relation to both theory and the real world derives from model construction where aspects of theory and the real world as well as outside elements like analogies and stories come in. Boumans (1999) provides such an account of model building which points out that building a model is a process that integrates various pieces including theoretical notions, empirical findings, metaphors, mathematizations, etc.

Other important issues raised in modern model accounts - beyond the dispute about the relationship between a model and the real world - relate to the functioning of models and address such questions as how do models help theorizing or understanding the 'real world', and how do we learn from models? Morrison and Morgan (1999) assert that a model, as a tool of investigation, requires some representation which is neither a mirroring of the world nor of the theory, but often entails elements of both. Hughes (1997), who focuses on mathematical models, develops an account of representation that he calls DDI account as it involves the three stages of denotation, demonstration and interpretation. He illustrates how a model, that represents 
(part of) a theory in an idealized world, can become a vehicle of communication for such a theory, that allows us to demonstrate theoretical conclusions. He argues that '[a] mathematical model should not be thought of simply as an idealization or an abstraction. Like an analogical representation, it provides us with [...] a life of its own' (Hughes 1997: S331).

Hesse (1963) discusses the role of analogies in the process of scientific theorization extensively. ${ }^{6}$ Positive and neutral analogies between the target system, the phenomena to be explained, and the source system, on which the model is based, help unveiling properties of the target system. Psillos (1995) extends Hesse's (1963) analogical approach to model-construction proposing that negative analogies do not obstruct this heuristic role of a model.

McCloskey's (1983) elucidation, which can be linked to Hesse's analogical account of modeling, brought metaphors to economists' attention. ${ }^{7}$ Klamer and Leonard (1994) advance the case that models are metaphorical and explain how metaphors function in economic science. Constitutive metaphors, as they call them, affect the way we think about the economy. Heuristic metaphors 'catalyze our thinking helping to approach a phenomenon in a novel way' (Klamer and Leonard 1994: 32). A heuristic metaphor is developed into an analogy which draws explicit parallels between the principle subject of the metaphor and the subsidiary subject. 'A model, then, is nothing more and nothing less than an explicitly, most often formally articulated analogy' (Klamer and Leonard 1994: 35).

McCloskey (1990a) extends the rhetorical perspective illustrating that stories provide a different way of understanding things, and that metaphorical explanations and narratives answer each other. ${ }^{8}$ At first glance it seems that both stand on their own, but in McCloskey (1990b) a co-existence of stories and metaphors, though an uneasy one, is recognized as Morgan (1999b) points out. Morgan (1999b) argues instead that models and stories are interdependent. Her account of stories focuses on the model-world relation and asserts that stories are a fundamental part of models. ${ }^{9}$

That a model is 'a story with a specified structure' had already been asserted by Gibbard and Varian (1978: 666), but their claim remains skeletal as a story in their perception seems to be merely an interpretation of mathematical symbols, rather related to the stages of denotation and interpretation in Hughes's (1997) DDI account than to the type of narrative considered by McCloskey (1990a). Although their important claim that 'a model poses a question of the form, "What would happen if such and such were the case?"' (Gibbard and Varian 1978: 668), could potentially set the stage for stories to come in, Gibbard and Varian remain on the non-narrative technical level and argue that the model provides deductive answers to such counterfactual reasoning. Morgan (1999b) explains that 'models have to be "questioned" to make use of their "internal dynamics", and answering the question using the "deductive resources" of the model typically involves 
storytelling' (Morgan 1999b: 8). Thus, story-telling is an essential element in exploring novel facts.

Morgan (1999a) elucidates that we learn from models about theory and the real world by constructing them and applying them. Applying the model is initiated, as Morgan (1999b) points out, by questions we pose; and it might involve making use of the 'internal dynamics' of the structure as described by Hughes, for example by changing parameters or shifting curves, or it might involve counterfactual reasoning.

The accounts considered in this section agree that models foster scientific exploration. Whether models only facilitate theory development or also inform our understanding of the real world remains disputed, however. Connected with this discussion about the relationship between models and the real world is the important debate about the realism of assumptions. Koopmans demands that theory should be developed with increasing realism, while the question of realistic assumptions is a subordinate one for Friedman who holds that ' $[. .$. ] theory is to be judged by its predictive power for the class of phenomena which it is intended to "explain", (Friedman 1953: 8). The importance that we ascribe to this debate hinges to some degree on the question about the purpose of models and their relation to the world. Hausman argues that unrealistic modeling is not an issue as long as one does not say anything about the world. In Friedman's view, economists search for valid and significant predictions rather than for an explanation or understanding of the real world. ${ }^{10}$ But understanding the real world is a major aim of modeling in Morrison and Morgan's view. By examining Hicks's modeling effort, Section 4 considers the significance of realistic assumptions and sheds some light on the relationship between models and the world.

How models facilitate scientific exploration is another important subject in model accounts. Different aspects of how models function have been proposed, but these aspects are discussed independently in different model accounts. The role of these elements - such as mathematical representations, analogies, metaphors or stories - is disputed and it is difficult to assess their relative importance. However, understanding the role of these different elements is crucial to realize what and how we can learn from models. Section 5 discusses the process of model building, the function of narratives, the role of representation and its implications for what can be learned from a model in relation to the case study. Section 6 examines thoroughly the question of how we learn from models.

\section{WHY DOES HICKS BUILD A MODEL?}

The proposition that economists build models because they help theorizing certainly applies to the case study. Hicks's motivation to build the IS-LL 
model stems from his uneasiness with the confusion present in scientific debate about Keynes's General Theory of Employment. ${ }^{11}$ He constructs the model to pin down the difference between classical theory and Keynes's theory, or, as he puts it himself, 'to be able to isolate Mr. Keynes's innovations, and so to discover what are the real issues in dispute' (Hicks 1937: 148). Consequently, he looks for new ways of classifying theoretical concepts in order to make the conflicting theories comparable in a common framework. This is consistent with the idea that '[a]n absolutely crucial part of the scientific enterprise [...] is the construction of new concepts, of new ways of classifying phenomena' (Hausman 1992: 26). Hicks succeeds in developing a conception of macroeconomic s which disaggregates a system of equations in two general parts: ${ }^{12}$ the IS part, which includes an investment function, a consumption function and a condition that savings equals investment, and the LM part, which typically consists of money demand and supply relations and an equilibrium condition.

Since Hicks's main intention is to compare theories, Hausman's view that models facilitate the conceptual exploration of theory and are not related to the real world seems appropriate at first sight. Closer examination, however, reveals that Hicks does not solely remain in the theoretical sphere. He is concerned with implications for the real world, which suffers from the mass unemployment of the Great Depression. He states, for example, that it 'follows from this theory that you may be able to increase employment by direct inflation' (Hicks 1937: 150).

Hausman would probably point out that a model only serves to explore theory, but that models make no empirical claims, so that the realism of assumptions of a model is irrelevant. In his view, models help in the construction of new theoretical concepts and provide the conceptual means for making 'claims about the world which may be tested and which may be true or false' (Hausman 1992: 25). It is theory that essentially makes assertions about the real world. The theories are then true or false, but the realism of the assumptions in the model would not matter. Yet, realistic assumptions do matter for Hicks and have an impact on his model. Hicks (1937) discusses, for example, on page 151, assumptions made on the money demand parameter $k$, the inverse of velocity: 'Changes in $k$ can be related to changes in confidence, and it is realistic to hold that the rising prices of a boom occur because optimism encourage s a reduction in balances [...]. But as soon as we take this step it becomes natural to ask whether $k$ has not abdicated its status as an independent variable'. He explicitly refers to observations of the real world saying that 'it is evident that total money income experiences great variations in the course of a trade cycle' (Hicks 1937: 150) and explains what implications this has for classical theory and the model. This observation of a real world phenomenon induces him to reconsider the plausibility of theory and to change the model allowing money demand to depend on the interest rate. 
In addition to these explicit references to real-world issues, Hicks probably thought carefully about the realism of assumptions and the relation of the model to the world. In his own account (see Hicks 1983), he emphasizes the importance of time as a real world phenomenon and considers the implications of the length of the period for a model. According to this discussion he has a period of particular length in mind when he says in his 1937 paper that he is dealing with a short period - in terms of his connotation this should refer to a week rather than a year - and this time period, familiar to him from his real world experience, matters for other assumptions like constant propensities or zero depreciation to be realistic. ${ }^{13}$

Hausman's view concerning the relation between models, theories and the real world is in my opinion too polarizing. Moreover, the dispute about whether a model is connected to the real world, or whether it is connected only with theory, while theory makes assertions about the world, does not serve the practicing economist well. Such a model builder probably looks for more pragmatic answers on what models are and what makes them useful.

Admittedly, much of Hicks's modeling is aimed at understanding theory, and not explicitly at understanding the real world, a view that is consistent with Gordon (1991), but there remains an important connection with the real world. Hicks's modeling rather fits Morisson and Morgan's (1999) account that the model mediates between theory and the world. Real world phenomena, like the conception of time or the existence of mass unemployment, as well as theoretical notions inform the model, both when building and manipulating it, and the model informs about theory and real world issues.

Hicks's construction of the mathematical version of a Keynesian model exhibits features that fit elements of Koopmans's account. For example, the detection that great variations in income, an observational fact informing the model, cannot plausibly be explained by the proposed classical model, i.e. does not follow from strict deductive reasoning, induces Hicks to change a crucial assumption of his model. This procedure seems logical since it enables to identify the assertions on which the different implications of classical and Keynesian theory rest which is clearly Hicks's intention. In that respect, it is difficult to refute Koopmans's view that economists build models as a way of tracing logical implications from postulates and expressing the complicated reality in a simpler way.

Yet, the phase of modeling does not receive much attention. Koopmans talks more about how we should think of a model once it has been constructed than about how it should be constructed. Once we see Hicks's model before our eyes, Koopmans's account helps explaining what models allow economists to do, but it does not provide a satisfying answer to the question how economists build models. This question is at least as important as the question why economists build models and is discussed next. 


\section{HOW DOES HICKS BUILD HIS MODEL?}

\subsection{Ingredients}

The construction of the IS-LM model is a good example to underline Boumans's (1999) account of model construction that is illuminated by the analogy of baking a cake without a recipe. Boumans explains that '[i]f you want to bake a cake and you don't have a recipe, $[. .$.$] you do not start blank,$ you have some knowledge about, for example, preparing pancakes and you know the main ingredients: flour, milk, raising agent and sugar. You also know how a cake should look and how it should taste' (Boumans 1999: 67). I would add that you do not only know what the cake should look or taste like, you also have a reason for baking the cake. What kind of cake you bake depends on your intention and the occasion you bake the cake for. Is taste more important or does quantity matter, or decoration? Hence, the purpose of building the model crucially impacts on the process of model building and especially on representation. The mode of representation matters. Not only what is chosen to be in the model but also what is deliberately left out and not represented has a bearing. While Boumans concentrates on the implications of such an integration for justification of the model $^{14}$, he is silent on how the 'ingredients' and the mode of representation also determine the limits of the model to serve as a tool of investigation and constrain what can be learnt from the model about theory and the world. This issue is addressed in Section 6 below.

As a result of his motivation to discover the root of different implications from the two competing theories, Hicks focuses on parts of the theories that address the same question and attempts to construct the models representing the theories analogously: 'I shall try to set out my typical classical theory in a form similar to that in which Mr. Keynes sets out his own theory' (Hicks 1937: 148). ${ }^{15}$ He deliberately leaves out anything from the theory that is not relevant to the problem, or as he puts it: 'I shall leave out of account all secondary complications which do not bear closely upon the special question at hand' (Hicks 1937: 148).

He only deals with a short period, which he defines as the period 'in which the quantity of physical equipment of all kinds available can be taken as fixed' (Hicks 1937: 148). By making this simplifying assumption he approximates reality. Hicks introduces additional simplifying assumptions - including for example, homogeneous labor, zero depreciation and a fixed nominal wage to make the model approximate reality. Hicks opts for a mathematical representation that allows to nest the models of classical and Keynesian theory in order to make comparison straightforward.

Besides using parts of Keynes's General Theory and what Hicks calls 'typical' classical theory as ingredients for his model, he adopts the idea of confronting 'classical' economics and Keynes's General Theory, which goes back to Keynes himself. ${ }^{16}$ Other ingredients include additional theoretical 
ideas and concepts like the Cambridge quantity equation or the marginal cost principle as well as observation s from the real world, for example the evidence of short-run fluctuations in income. Moreover, he borrows from the existing mathematical representations by Harrod (1937) and, especially in terms of notation, from Meade (1937) who uses a two sector model, a widespread mode of representing the economy at the time. ${ }^{17}$ Finally he seems inspired by the diagram with supply and demand curves that is commonly used in demand theory. Hicks (1983) claims that the IS-LM diagram was inspired by his work on Value and Capital, especially by work on three-way exchange, conceived in a Walrasian manner, for which he had already found a graphical representation in a two-dimensional diagram. Although Young (1987) does not doubt Hicks's originality, he argues (1987) that Champernownes's (1936) paper might well have catalyzed Hicks's thought to a combined equationaldiagrammatic representation of his interpretation of Keynes's General Theory. ${ }^{18}$

Hicks composes these ingredients in a way that offers new insights. The really important innovation is the representation of the model in a diagram, a new tool that opened up a whole new avenue of thinking, manipulation, exploration and understanding. The graphical representation probably satisfied many economists' innate demand for a more accessible account of the essentials of Keynes's argument.

\subsection{Theoretical representation - providing structure}

When building the mathematical models formalizing Keynesian and classical theory he draws on, as Darity and Young (1995) also point out, Meade's (1937) assumptions that the nominal wage is fixed, that output equals the production of investment and consumption goods, that total employment equals the sum of employment in both sectors, and that output prices in both sectors depend on marginal product factor pricing. Furthermore Hicks adopts a simplified version of the 'Cambridge Quantity Equation' which postulates a definite relation between the demand for money and income in the mathematical representation of classical theory. He closes the model by assuming that investment depends on the rate of interest and that saving equals investment where savings also depend on the interest rate and income. Hicks summarizes his mathematical representation by three fundamental equations:

$$
M=k I, I_{x}=C(i), I_{x}=S(i, I),
$$

where $M$ is money supply, $k$ inverse velocity, $I_{x}$ the value of investment, $C(i)$ represents the marginal-efficiency-of-capital schedule and $S(i, I)$ saving as a function of the interest $i$ and income $I$. If we did not know what these mathematical symbols and letters stood for, the mathematical model would 
undoubtedly not be a meaningful representation of the above mentioned concepts and assumptions. Hicks assigns letters, mathematical symbols, functional relations and derivatives to the economic phenomena that the mathematical model should represent. Hughes (1997) defines this denotation in his DDI account. It starts with the sentence 'Let us begin by assuming that $w$, the rate of money wages per head, can be taken as given' (Hicks 1937: 148) and ends on page 149 just before the introduction of the three fundamental equations. In this passage, he also identifies what the relation between the symbols - or the concepts they represents - are, for example ' $I_{x}$ is therefore a function of $N_{x}, I$ of $N_{x}$ and $N_{y}$ ' (Hicks 1937: 148). $N_{x}$ and $N_{y}$ denote 'the numbers of men employed' in producing investment goods, $x$, and consumption goods, $y{ }^{19}$

The other two stages of Hughes's DDI account, namely demonstration and interpretation, can also be recognized in Hicks's modeling. Once the mathematical symbols and functions are denoted, mathematical rules can be exploited to arrive at new mathematical relations, for example mathematical expressions for the three unkowns $I, I_{x}$ and $i$. This stage of demonstration starts with the sentence: 'Let us consider some properties of this system' (Hicks 1937: 149). An algebraic rule determines an outcome, e.g. '[i]t follows directly from the first equation that as soon as $k$ and $M$ are given, $I$ is completely determined' (Hicks 1937: 149). Such a mathematical result is then interpreted in terms of the phenomena that are modeled ('that is to say, total income depends directly upon the quantity of money', Hicks 1937: 149) and given economic meaning in the interpretation stage. More such examples follow, which focus for instance on a rightward movement of the schedule of the marginal efficiency of capital or an increase in $M$. Hicks also considers changes in assumptions, e.g. he relaxes the assumption that the nominal wage is fixed and works out the implications by deductive reasoning using the mathematics, or the internal dynamics in Hughes terminology, which govern the system.

Hughes (1997) does, however, not answer what sets the internal dynamics in motion. An examination of Hicks's modeling reveals that questions about theory and the world drive the use of mathematics. The question of what consequences an increase in the inducement to invest has leads him to shift the $C(i)$ schedule rightward in the model. Similarly, the question of what effect an increase in money supply has on the world in the model induces him to investigate the consequences of an increase in $M$, the variable representing money supply, in the mathematical model. That narratives in form of questions set the internal dynamics provided by the mathematical structure in motion, confirms a point made also by Morgan (1999b: 9): 'We choose and pose the questions, and use the mathematics or other resources of the metaphor or the structure to help us answer them. Our questions are the 'external dynamic' which enables us to make use of the 'internal dynamics' of the structure noted by Hughes'. 


\subsection{The role of stories - showing how the structure works}

Gibbard and Varian's (1978) definition of a model as 'a story with a specified structure' is underpinned by the case study which reveals that the mathematical form provides the structure which needs an element of interpretation. ${ }^{20} \mathrm{~A}$ story offers such an interpretation. But the case study shows that the role of the story is more essential than it is in their view, in which the interpretation and hence the story reduces to a mere interpretation à la Hughes: ' $\ldots$ we can think of the story as telling what kind of extension each predicate has and what kind of domain each quantifier has: a model will talk of firms, consumers, preferences, prices, information, and the like' (Gibbard and Varian 1978: 666). A story connects the mathematics to the facts of the world that is modeled; it provides a transmission channel and shows how the structure works. The narrative reasoning defines the sequence of events and argues that there is a causal relation, which is not necessarily obvious from the mathematical structure. ${ }^{21} \mathrm{~A}$ rise in income due to an increase in the money supply in the classical model is obvious. But it is not clear why the parameter $k$, which is fixed in the mathematical model, should be affected during the transmission, something that Hicks must have in mind saying that 'people will increase their spending and lending until incomes have risen sufficiently to restore $k$ to its former level' (Hicks 1937: 149; emphasis added). The story refers to phenomena and observations of the real world like spending and lending that are not explicitly referred to in the mathematical model. This supports Morgan's (1999b) view that narrative elements enable us to apply the structure of a model directly onto the facts of the world.

By using the structure of a model and telling a story with it that is consistent with this structure, we explain facts of the world. In that sense, stories are directed towards understanding the world. In addition, narrative reasoning of the kind 'What happens if . . ' helps to uncover limitations of the model imposed by its structure or by unrealistic assumptions, which also fosters learning about the world and theory. For example, the precise nature of the 'short-run', for which the IS-LM equilibrium is defined, is only discovered when telling a story, as Hicks does in his original paper by pointing out that it is a period 'in which the quantity of physical equipment of all kinds available can be taken as fixed' (Hicks 1937: 148) or in his 1983 reassessment in the passage: 'I called it a week. Much more can happen in a year than a week [...] I wanted to avoid much happening, [ . . . So it was that I made my markets open only on a Monday; what actually happened during the ensuing week was not to affect them' (Hicks 1983: 51). Here the story unveils a major shortcoming of Keynes's theory or at least of the IS-LM approach to it as Hicks (1983: 51) notes: 'But the point of it was to exclude the things that might happen, and must disturb the markets, during a period of finite length; and this, as we shall see, is a very real trouble in Keynes'.

A story, or narrative reasoning, is by no means unique. ${ }^{22}$ It is therefore 
itself a theoretical view which is more or less plausible. Alternative transmission mechanisms might become apparent. It is by unveiling these alternative views, that stories help enlarging our theoretical knowledge. While reasoning that a change in nominal wages causes real wages to rise and employment to fall, it also becomes clear that an equiproportional rise in prices leaves the real wage and the level of employment unchanged - which Hicks admits by the qualification 'unless the price-level rises' (Hicks 1937: 150). Clearly, much of the dispute among macroeconomists in the following years centered on the plausibility of such transmission channels, i.e., on the question how well it squares with our real world experience.

It is by a similar kind of narrative sequence that Hicks illustrates that classical theory cannot plausibly explain the real-world phenomenon of shortrun fluctuations of income. Hicks considers several possible transmission channels, given that income is determined by the Cambridge quantity equation, including variations in $M$, in $k$ and changes in the distribution, which all make reference to the real world. Hicks states for example that 'the variations in $M$ that are traceable during a trade cycle are variations that take place through the banks - they are variations in bank loans' (Hicks 1937: 151). An analogy, 'thinking of banks as persons', connects the behavior of banks to that of persons, and so indicates that the interest rate first falls, a phenomenon that the classical model does not take account of. Discussing changes in $k$, he refers to pessimism and optimism. Reference to such real world phenomena, which are outside the mathematical model, reveals that the assumption of an independent $k$ might not be a good approximation of reality. Convincing transmission channels suggest that money demand depends on the interest rate. Finally, he refers to the marginal principle derived in value theory to motivate that holding money involves a sacrifice of interest.

\subsection{Changing the assumptions - analogous modeling}

Real world observations and the plausible theoretical assumption that money demand depends on the interest rate leads him to replace the Cambridge quantity equation from the classical model by a negative functional relation between money demand and the interest rate in the Keynesian model. In addition, he postulates for the Keynesian model that savings are independent of the interest rate. Hicks's mathematical model of Keynes's theory is an analogy to the classical model because the mathematical representation of the Keynesian model as a three equation system - given by: $M=L(i), I_{x}=C(i)$, $I_{x}=S(I)-$ draws an explicit parallel between them. Positive analogies include the second equation that describes investment demand and the condition that savings equals investment. Whether the differences between the systems - that money demand depends on the interest rate but not on income, and that savings are independent of the interest rate in the Keynesian model - should be called neutral analogies or negative analogies is not 
obvious. In the language of Psillos (1995) we could probably call them neutral analogies since we do not know yet whether they lead to properties that the Keynesian model and the classical model share or properties that make them different. I propose, however, to think of these differences as negative analogies since we would lean to tell different stories with the equations individually considered. As Hicks also notes, a change in money supply affects the interest rate in the Keynesian model, whereas an increase in investment demand raises income.

By assessing the consequences of the differences in the three equations, the negative analogies, Hicks learns more about Keynes's theory - namely that liquidity preference is vital, while the assumption that savings are independent of income is not (see Hicks 1937: 152, especially footnote 4) - and about his model of Keynesian theory, i.e., that the 'dependence of the demand for money on interest does not, in the end, do more than qualify the old dependence on income' (Hicks 1937: 152). This finding induces him to restate his mathematical representation of the General Theory as

$$
M=L(I, i), I_{x}=C(i), I_{x}=S(I) .
$$

Hicks notes the similarity of this mathematical structure and that of the classical model, which leads into the discussion whether Keynes's theory is merely a special case of the revised and qualified Marshallian theories. In view of his argument that the assumption of savings being independent of the interest rate is 'ultimately insignificant', it is not clear, however, why he does not present the nesting model

$$
M=L(I, i), I_{x}=C(i), I_{x}=S(i, I)
$$

to underpin his argument. ${ }^{23}$

Building the mathematical model clearly fosters learning, but the quality of what is learned depends, as Morrison and Morgan (1999) would probably consent, on the quality of the representation of the world that the model provides. Does Hicks present classical theory and Keynesian theory appropriately? Some critics, including Keynes himself, have answered in the negative. $^{24}$

\subsection{Alternative modes of representation}

As a final step of model construction, Hicks offers a diagram which helps solving the system graphically. He represents the first equation as an upward sloping line, the LL curve, in the interest-income space. The other two equations taken together are depicted as a downward sloping line, the IS curve. While the slopes follow directly from the mathematical system, the representation of the economic system as a two-dimensional graph consisting of two curves in the interest-income space is the real innovation of the paper and was according to Young (1987: 41) 'the object of almost immediate and 
overwhelming acceptance and recognition'. ${ }^{25}$ Although its validity has been contested ever since, Hicks's IS-LM approach became the workhorse model of macro-economist and is probably the most widely used representation of Keynes's General Theory.

The diagram reminds one of the graphical representation of demand and supply schedules in the price-quantity space that are commonly used in consumer theory. Hicks explicitly refers to this analogy to elucidate that income and the interest rate are determined simultaneously, "just as price and output are determined together in the modern theory of demand and supply' (Hicks 1937: 153). The graphical representation thereby alludes to the notion of equilibrium, which is well understood by economists.

In his later work, Hicks (1983) points out that he spotted an analogy between key elements in Keynes theory - the consumption function, marginal efficiency of capital and liquidity preference viewed as the market for goods, the market for bonds and the market for money - and a Walrasian system of three-way exchange with two independent prices determined by equilibrium in two markets. Upon the conjecture that the Walrasian analogy holds for the Keynesian system, its equilibrium would be determined by the intersection of the IS and the LL curves which represent equilibrium in the goods market and the money market.

Because of the negative analogy that all markets clear in Walras's model, but not in Keynes's model, it is not clear that this conjecture is valid. It is interesting to note here that we explore theory by assessing, as Hicks (1983) does, the consequences of such a negative analogy on the main outcome of the model. We do not only learn from Hicks (1983: part II) under which conditions the Walrasian analogy holds with fixprice markets, but also that the flow of time is crucial. Thereby we learn about the limits of the graphical representation and the model as a whole, along the lines described by Hicks (1983: 58-9).

The mode of representation determines how and what can be learned. Representations shape and constrain what can be learned. Some modes of representation might be more useful to foster learning about particular theoretical aspects or real world phenomena than others. The graphical representation of the IS-LM model seems to have become so successful because it enabled economists to discover relationships which they might have failed to notice with other modes of representation. But the graphical representation also has its limits and it sometimes hides the shortcomings of the underlying model.

The diagram provides reduced form relations. It summarizes the structure of the complicated mathematical system and makes obvious how the system responds to changes by enabling us to see what the new equilibrium will finally look like. It separates the discussion how the new equilibrium can be characterized from the discussion about the transition to it. Although it provides some indication about the transmission channel, since we determine 
which curve shifts, the graphical representation generally does not explain the chain of events that bring us to the new equilibrium nor does it tell how we get there. This might be helpful in certain situations, but clearly shows the limitations of the diagram.

Another limitation of the diagram is the lack of a metric. It is in relative terms in Hicks's paper so that it is not possible to read off the size of certain shocks or (policy) changes that affect the system and shift the curve. However, once we know the slopes of the curves and the size of shifts and provide a metric - which we might determine econometrically - the diagram can serve as a measurement tool. Then, it allows to make statements about how strong certain relations must be or which requirements must be satisfied to explain a given outcome.

\section{USING THE MODEL AS AN INSTRUMENT TO INVESTIGATE THEORY AND THE WORLD}

In this section, I consider Gordon's and Morrison and Morgan's claim that models can function as a tool of scientific investigation. I examine how the diagram functions as an instrument for exploring and experimenting on the General Theory (as interpreted by Hicks) and investigate what we learn from the assumptions .

We learn about theory by shifting curves in the diagram. The diagram makes evident how changing parameters in the model simultaneously affects income and the interest rate. It provides a definite solution, a point of intersection representing a combination of income and the interest rate, without having to consider all the single effects and relations that are modeled. The diagram helps theorizing since it allows one to disentangle complex relations. Separate elements might have offsetting effects in theory which sometimes makes it difficult to grasp what the outcome is, especially when some indeterminacy seems to exist (for example, an increase in the inducement to invest tends to raise the interest rate, which decreases money demand such that income has to rise to establish equilibrium, but the supply of savings tends to increase in response to rising income which depresses the interest rate).

In part 3, Hicks (1937) first points out that a change in the inducement to invest shifts the IS curve. As long as the LL curve has a positive slope, this changes both income and the interest rate in the same direction. Such an outcome is contrary to Keynes's view that the interest rate is not affected. The diagram makes clear that Keynes's special theory is consistent with the model if and only if the LL curve is horizontal. In addition, the diagram teaches us that the magnitude of the change in the interest rate depends on the slope of the curves: The flatter the LL curve, the less pronounced is a change in the interest rate and the bigger is the change in income for a given shift of the IS curve. This motivates Hicks to theorize on the slope of the LL curve. He 
argues that the curve is nearly horizontal on the left and nearly vertical on the right since there is a minimum interest rate and a maximum amount of income that can be financed with a given amount of money.

He then goes back to the model to incorporate this observation and observes what this causes in the diagram - the LL curve is horizontal at the minimum interest rate and vertical at the maximum income that can be financed with a given amount of money - to infer the consequences of a minimum interest rate and a maximum income for theory. If we are in a situation where the IS curve intersects the LL curve in the range where it is horizontal, i.e., in a depression when income is low and the interest rate has reached a minimum, changes in monetary policy cannot affect neither the interest rate nor income. It is again by shifting a curve, the LL curve, that Hicks reaches the conclusion. This example demonstrates how the model mediates between the world and theory. An observation, phenomenon or assumption (a minimum interest rate) is transferred to the model (incorporated in the slope of a curve), the outcome resulting from changes in the parameters (change in money supply) is studied in the model (shift in the LL curve) and then incorporated in theory (liquidity trap). The model can serve as such a mediating tool because it incorporates neither just theory, nor just observation.

Moreover, the model mediates between classical theory and Keynes's theory, as it makes apparent that none of these two theories offers a superior explanation of the functioning of the economy in all situations. Instead, each theory better enlightens certain aspects of the economy - and more convincingly describes its functioning in distinct economic conditions - than the other. Classical theory is a good approximation if the IS curve intersects the LL curve in the steep part while Keynes's theory becomes valid if the IS curve intersects the LL curve in the horizontal part. Hicks concludes: 'So the General Theory of Employment is the Economics of Depression' (Hicks 1937: 155). Hence, the Keynesian model or the classical model is applied successfully only in specific situations, i.e., when the assumptions are realistic. The conclusions of the applied model are approximately true if the assumptions are close to the truth. The diagram can be used as a counterfactual as discussed by Gibbard and Varian (1978). Starting from assuming that assumptions are true of the world we consider what happens if something changes in the model. So we could use the model to analyze a change in money supply if the assumptions of the Keynesian model are assumed to be true. ${ }^{26}$ The assumptions of both the classical and the Keynesian model are neither true of all states of the world, but in specific cases the assumptions are good approximations. It is in these situations that the theory provides valid conclusions.

Hicks recognizes that these two theories do not exhaust all possible real world situations and therefore generalizes the mathematical model in part 4 by postulating that income and the interest rate affect all equations. This 
yields a system that nests not only the classical and Keynesian model constructed in the first two parts of the paper, but also incorporates the possibility that investment demand depends on income:

$$
M=L(I, i), I_{x}=C(i, I), I_{x}=S(i, I)
$$

This manipulation helps him to discover how crucial Keynes's assumption, that saving is independent of the interest rate, really is. By using the diagram he is able to show that the elasticities of both saving and investment with respect to the interest rate and income determine the slope of the IS curve. In the framework that he has now at his disposal he can discuss the effects of different slopes of the IS curve and the LL curve. When he shifts curves or changes slopes of the curves he tells stories of what happens when moving from one equilibrium point in the model to another or explains what motivates the different slopes. It is this narrative that connects the model with theory and the world.

\section{CONCLUSION}

Not least because the purpose of building a model determines its form, there cannot exist a representative model in economics so that different categories of models might accentuate different aspects raised in theoretical model accounts, rendering models mainly deductive, mainly metaphoric, mainly instrumentalist, etc. However, the analysis of the IS-LL model is, despite its case-study character, useful in assessing such model accounts. It clearly indicates that polarizing definitions of models, for example as either mathematical structures, metaphors, or stories, is deficient. Rather, models entail many elements, which have an effect on how and what we can learn from models about theory and the world.

The case study of the construction of the IS-LL model suggests that economists build models because models help exploring theory and the world, thus supporting the argument of Morrison and Morgan (1999). Consistent with Gordon's (1991) view, Hicks's modeling aims at understanding and exploring theory. Yet, for Hicks - and this is somewhat inconsistent with Hausman (1992) and certainly in conflict with Friedman's (1953) view - the realism of assumptions matters. Real world phenomena influence and inform his model.

In addition, Hicks's modeling effort suggests that models are not solely built to explore the theoretical sphere, but also to improve our understanding of the real world. Models can serve as an instrument of investigation when their 'internal dynamics' are taken advantage of. This process is often initiated by a question. Stories provide interpretations to such questions and help to connect the structure of the model to facts of the world that the model should explain. Narrative reasoning also advances theorizing by unveiling alternative 
transmission mechanisms that enlarge our theoretical knowledge. In that sense, stories foster the mediation between models, theory, and the real world. Stories are therefore an essential part of models as Morgan (1999b) argues.

Models can serve as instruments or tools of investigation as Morrison and Morgan (1999) claim because they are by construction partially independent of both theory and the world. Model construction is an integration process (Boumans 1999) which requires choosing some form of representation. Economists already learn about theory and the world when arranging different elements to create a new model. This process and the mode of representation are influenced by the purpose for which a model is built. Representation determines and shapes what can be learnt from a model and how a model can be used, thus inevitably determining the value of a model.

\section{Thomas J. Dohmen \\ Maastricht University \\ t.dohmen@mw.unimaas.nl}

\section{ACKNOWLEDGEMENTS}

I am grateful to Mary Morgan for her inspiring ideas and very useful remarks. I thank Roger Backhouse for his constructive comments on an earlier version of the paper. Suggestions by three anonymous referees greatly improved the paper. None of these persons necessarily share the views expressed in this paper and any errors or omissions remain my responsibility, of course.

\section{NOTES}

1 The core ideas of this section are similar to the point of view of Leijonhufvud (1997).

2 Lionel Robbins (1984) makes this case placing the chief postulates almost beyond doubt.

3 Friedman declares that '[v]iewed as a body of substantive hypotheses, theory is to be judged by its predictive power for the class of phenomena which it is intended to "explain". Only factual evidence can show whether it is "right" or "wrong" or, better, tentatively "accepted" as valid or "rejected". [ ... The only relevant test of the validity of a hypothesis is comparison of its predictions with experience. The hypothesis is rejected if its predictions are contradicted [...]; it is accepted if its predictions are not contradicted [...]' (Friedman 1953: 8); and he rejects the idea that the conformity of these 'assumptions' to 'reality' is an additional test of the validity of the hypothesis by saying that this view is 'fundamentally wrong and productive of much mischief' (Friedman 1953: 14).

4 A similar point of view is expressed by Gibbard and Varian (1978).

5 Note however that they do not maintain Friedman's view of instrumentalism.

6 Hesse's account bears the influence of the view of the English physicist N.R. Campbell (1920) who wrote that analogies 'are an utterly essential part of theories, 
without which theories would be completely valueless and unworthy of the name' (Campbell 1920: 129).

7 See also McCloskey (1990).

8 McCloskey states that '[i]t has doubtless been noticed before that the metaphorical and the narrative explanations answer to each other. [....] A story answers a model. Likewise, a model answers a story' (McCloskey 1990a: 61).

9 Morgan (1999a) states in the introduction that '[ . . . stories are neither "merely heuristic" nor "just rhetoric" but an essential part of the way models are used'.

10 Friedman begins his account of positive economics with the claim that '[t]he ultimate goal of a positive science is the development of a "theory" or "hypothesis" that yields valid and meaningful (i.e., not truistic) predictions about phenomena not yet observed' (Friedman 1953: 7).

11 See Hicks (1937: 147).

12 Actually there is a third block, the employment block, which represents the supply side of the economy. It generally consists of an aggregate production function, from which labour demand is derived, and a labour supply function.

13 Hicks (1983: 51) states: 'I called it a week. Much more can happen in a year than a week [... ] I wanted to avoid much happening, so that my (flexprice) markets could reflect propensities (and expectations) as they are at the moment. So it was that I made my markets open only on a Monday; what actually happened during the ensuing week was not to affect them'.

14 Contrary to the dominating view that empirical assessment takes place after the model is built so that discovery and justification are disconnected (cf. for example Hausman 1992), Boumans (1999) argues that justifications can be built-in because some 'ingredients' are empirical data or facts.

15 Note that this modeling approach illustrates that the same model, or at least a similar model, may sometimes be derived from more than one theory.

16 Hicks might also have been inspired by Harrod (1937), who attempts to draw the partition between Keynes and the classics. Young (1987) presents evidence based on Hicks's personal correspondence which shows that he had read the paper prior to writing down his own model. Both papers were presented in the session on Keynes's General Theory at the 1936 Econometric Society meetings in Oxford. It is also suggestive that the titles are similar: "Mr Keynes and Traditional Theory' and 'Mr. Keynes and the "Classics"; A Suggested Interpretation'. According to Young, Hicks knew also Meade's (1937) paper, the third paper presented in the same session, before writing up his own. (See Young, 1987, especially page 33 where a letter to James Meade is reprinted.)

17 This view is also upheld by Young (1987). In addition, Darity and Young (1995) provide a detailed comparison of the mathematical systems in Harrod (1937), Hicks (1937) and Meade (1937) and demonstrate that the underlying forms are identical. Hicks (1983) himself claims however, referring to two papers (Hicks $1935 \mathrm{a}$ and 1935b) published in 1935, that the model was already in his mind much earlier.

18 See also the discussion on some early mathematical and graphical representations of Keynes's General Theory in Darity and Young (1995).

19 It is interesting to note here that Hicks refers explicitly to 'men' rather than to 'workers' which is a hint - although a subtle one - that he is influenced by the real world, where commonly men worked in industry. It certainly implies that Hicks wants to understand the real world and that part of his modeling is devoted to modeling the real world. 
20 Compare with Gibbard and Varian's (1978: 666) view: 'The structure is given by the logical and mathematical form of a set of postulates, the assumptions of the model. The structure forms an uninterpreted system [...]'.

21 The causal relation runs from increases in money supply to increased money holdings and a fall in the parameter $k$ which measures velocity - this is not explicitly in the story - and then via higher spending and lending to higher income while $k$ increases to its initial level.

22 The argument is supported by recalling that Meade, Harrod and Hicks told different stories despite the obvious similarity of the underlying mathematical structure of their three models. In addition, their models were also conceived much differently by the audience at the Oxford conference, that, quite remarkably, seems to have overlooked 'the similarity between the equational representation in Harrod's and Hicks's papers' (Young 1987: 41).

23 Note that Hicks refers to a nesting model, which consists of the equations $M=L(I, i), I_{x}=C(i, I), I_{x}=S(i, I)$, in part 4 of the paper.

24 Keynes criticized Hicks for representing neither classical nor Keynesian theory appropriately, for implicit in his model remains the conclusion that money is not neutral in the classical model, and even worse that monetary policy is neutral in the representation of Keynesian theory (see Darity and Young 1995). However, the main point of his critique is, according to Young (1987), that the IS-LM approach does not take uncertainty into account.

25 Young (1987) reports on page 54 that "What was "new" and became the talkingpoint among participants of the symposium, according to George Shackle and Arthur Brown, was "the diagram",

26 Gibbard and Varian (1978) argue that the assumptions are said to be approximately true if the model is applied successfully. This is a somewhat odd conclusion because the example shows that neither model is true in all situations.

\section{REFERENCES}

Boumans, M. (1999) 'Built-in justifications', in M.S. Morgan and M.C. Morrison (eds) Models as Mediators, Cambridge: Cambridge University Press: pp. 66-96.

Campbell. N.R. (1920) Physics: The Elements, Cambridge: Cambridge University Press.

Champernowne, D.G. (1936) 'Unemployment, basic and monetary: classical analysis and the Keynesian', Review of Economic Studies 3: 201-16.

Darity, W. and Young, W. (1995) 'IS-LM: an inquest', History of Political Economy 27: $1-41$.

Friedman, Milton (1953) 'The methodology of positive economics', in M. Friedman (ed.) Essays in Positive Economics, Chicago: Chicago University Press: pp. 3-43.

Gibbard, A. and Varian, H. (1978) 'Economic models', Journal of Philosophy 75: 664-77.

Gordon, S. (1991) 'The methodology of modelling', in S. Gordon: The History and Philosophy of Social Science, London: Routledge: pp. 100-10.

Harrod, R.F. (1937) 'Mr. Keynes and traditional theory', Econometrica 5: 74-86.

Hausman, D.M. (1992) 'On the conceptual structure of neoclassical economics - a philosopher's view', in Essays in Philosophy and Economic Methodology, Cambridge: Cambridge University Press: pp. 25-32.

Hesse, M.B. (1963) Models and Analogies in Science, London: Sheed \& Ward.

Hicks, J.R. (1935a). 'A suggestion for simplifying the theory of money', Economica 3: pp. $1-19$. 
Hicks, J.R. (1935b). 'Wages and interest: the dynamic problem', Economic Journal 45: 456-68.

Hicks, J.R. (1937) 'Mr Keynes and the "Classics"; a suggested interpretation', Econometrica 5: 147-59.

Hicks, J.R. (1983) 'IS-LM: an explanation', in J.-P. Fitoussi (ed.) Modern Macroeconomic Theory, Oxford: Basil Blackwell: 49-63.

Hughes, R.I.G. (1997) 'Models and representation', Philosophy of Science 64: S325-36.

Klamer, A. and Leonard, T.C. (1994) 'So what's an economic metaphor?', in P. Mirowski (ed.) Natural Images in Economic Thought. Cambridge: Cambridge University Press: pp. 20-51.

Koopmans, T.J. (1957) Three Essays on the State of Economic Science, New York: McGraw Hill.

Leijonhufvud, A. (1997) 'Models and theories', Journal of Economic Methodology 4(2): 193-98.

McCloskey, Donald N. (1983) 'The rhetoric of economics', Journal of Economic Literature 21(2): 434-61.

McCloskey, Donald N. (1990a) 'Storytelling in economics', in D. Lavoie (ed.) Economics and Hermeneutics, London: Routledge: pp. 61-75.

McCloskey, Donald N. (1990b) If You're So Smart, Chicago: Chicago University Press.

Meade, J.E. (1937) 'A simplified model of Mr. Keynes' System', Review of Economic Studies 4(2): 98-107.

Morgan, M.S. (1999a) 'Learning from models', in M.S. Morgan and M.C. Morrison (eds) Models as Mediators, Cambridge: Cambridge University Press: 347-88.

Morgan, M.S. (1999b) 'Models, stories and the economic world', Working Paper.

Morgan, M.S. and Morrison, M.C. (1999) 'Models as Mediating Instruments', in M.S. Morgan and M.C. Morrison (eds) Models as Mediators, Cambridge: Cambridge University Press: pp. 10-37.

Psillos, S. (1995) 'The cognitive interplay between theories and models', in W.E. Herfel, W. Krajewski, I. Niiniluoto and R. Wojcicki (eds) Theories and Models in Scientific Processes, Amsterdam: Rodopi: pp. 111-15.

Robbins, L. (1984) [1932] An Essay on the Nature and Significance of Economic Science. 3rd edn. London: MacMillan Press.

Young, W. (1987) Interpreting Mr. Keynes: The IS-LM Enigma. Boulder, Colorado: Westview. 
Copyright of Journal of Economic Methodology is the property of Routledge, Ltd. and its content may not be copied or emailed to multiple sites or posted to a listserv without the copyright holder's express written permission. However, users may print, download, or email articles for individual use. 